\title{
THE IMPACT OF INTRAMUSCULAR-INSERTED HOOKED WIRE ELECTRODES AND SPECIFIC STIMULATION PARAMETERS
}

\author{
Arnold D ${ }^{1}$, Guntinas-Lichius $\mathrm{O}^{2}$ \\ ${ }^{1}$ Institute of Systematic Zoology and Evolutionary Biology with Phyletic Museum, FSU Jena, Germany \\ ${ }^{2}$ University Hospital, Friedrich-Schiller-University Jena, Germany \\ d.arnold@uni-jena.de
}

\begin{abstract}
The importance of FES (functional electrical stimulation) with hooked wire electrodes increases in the diagnostic and therapy methods in the last years. These new potential approaches make it necessary to impale the target muscle and stimulate them. In our pilot experiments we determine how intense the target muscle was injured by repeated impalement with hooked wire electrodes and subsequent electrical stimulation. The triceps brachii muscles of 10 female rats were investigated. Typical signs of mechanical muscle injury and subsequent regeneration can be observed. We can assume that the stimulation protocol had no undesired side effects on muscle structure and function.
\end{abstract}

Keywords: muscle, injuries, stimulation, hooked wire, rat

\section{Introduction:}

FES with needle EMG (electromyogram) electrodes becomes more and more important (Cheetham et al. 2011). The information outcome of the EMG technique by itself is limited (Kim et al. 2012). Just the activity of a small area of the muscle can be registered. Because of the many necessary changes of the needle position by the investigator the muscle is injured with each trial to analyze its operational capability. The FES is an additional diagnostic tool and increases the possibilities to describe the paretic dysfunction. It supports the differentiation between intact and paretic parts. This is important if muscle compartments are able to fulfill different functions, like the PCA muscle (M. cricoarytenoideus posterior) of the larynx (2 or 3 different compartments Sander et al. 1993, 1994). Therapies to reduce aberrant patterns of muscle recruitment and, thus, improve muscle function (Colton et al. 2006) are another wide field for FES with needle electrodes. It can help to relax spasm, restore the natural muscle function (facial nerve paresis) or reduce symptoms of phantom pain. The target muscle will be impaled and stimulated often by all these techniques. In our pilot experiments we determine how intense the target muscle was injured by the insertion of hooked wire electrodes and subsequent electrical stimulation with prevalent parameters.

\section{Material \& Methods:}

The left and right triceps brachii muscles of 10 female rats (Han Wistar) were impaled with monopolar hooked wire electrodes (CareFusion Injection Needle $\varnothing 0.51 \mathrm{~mm}$ ) and a third electrode was placed subcutaneously into the back. The left triceps muscle was stimulated with a Neurosign 100 for 1,3 or 5 hours with $30 \mathrm{~Hz}$ and $1 \mathrm{~mA}$ (rectangular, monophasic pulses with $200 \mu \mathrm{s}$ duration) under isoflurane anesthesia (Table 1). Slightly contractions of the muscle were visible at the beginning. The right muscle was not stimulated and served as a control. The animals were euthanized one or four days after the last stimulation. The muscles were dissected and frozen in isopentane pre-cooled in liquid nitrogen. Serial cross sections $(20 \mu \mathrm{m}$ thick) of the muscles were prepared using a cryostat (CM1850, Leica Microsystems) and stained with toluidine blue or haematoxylin-eosin.

Table 1: Stimulation protocol.

\begin{tabular}{llll}
\hline Animal & $\begin{array}{l}\text { Total } \\
\text { dura- } \\
\text { tion of } \\
\text { No. } \\
\text { lation } \\
\text { lation } \\
\text { (days) }\end{array}$ & $\begin{array}{l}\text { Stimu- } \\
\text { lation } \\
\text { dura- } \\
\text { tion }\end{array}$ & $\begin{array}{l}\text { Survival } \\
\text { after last } \\
\text { stimulation } \\
\text { (days) }\end{array}$ \\
\hline 1 & 1 & 5 & \\
2 & 1 & 5 & 4 \\
3 & 5 & 3 & 4 \\
4 & 5 & 3 & 4 \\
5 & 5 & 1 & 4 \\
6 & 5 & 1 & 4 \\
7 & 5 & 3 & 1 \\
8 & 5 & 3 & 1 \\
9 & 5 & 1 & 1 \\
10 & 5 & 1 & 1 \\
\hline
\end{tabular}




\section{Results:}

In all investigated triceps muscles we observed circumscribed areas containing small basophilic (regenerating) muscle fiber profiles (Fig. $1 \mathrm{~A}, \mathrm{~B}, \mathrm{C}$ ) and, less commonly, necrotic fibers surrounded by moderate cellular infiltration. These are typical signs of mechanical muscle injury and subsequent regeneration (Irintchev \& Wernig 1987). The damaged areas could be traced in serial sections over distances of many millimeters $(5-10 \mathrm{~mm})$ and apparently represented penetrating wounds caused by the wire electrodes. Single injury tracks were seen in muscles impaled only once (animals 1 and 2 in Table 1) and multiple (3-5) tracks were found in the rest of the muscles. The extent of muscle damage was small. Injury tracks in single sections were restricted to $10-20$ fibers and the overall volume of tissue injury was certainly well below $1 \%$ of the muscle volume. Outside damaged areas, the muscle fibers had normal appearance and no cellular infiltrates were visible. No differences were detected between stimulated (left) and nonstimulated (right) muscles.

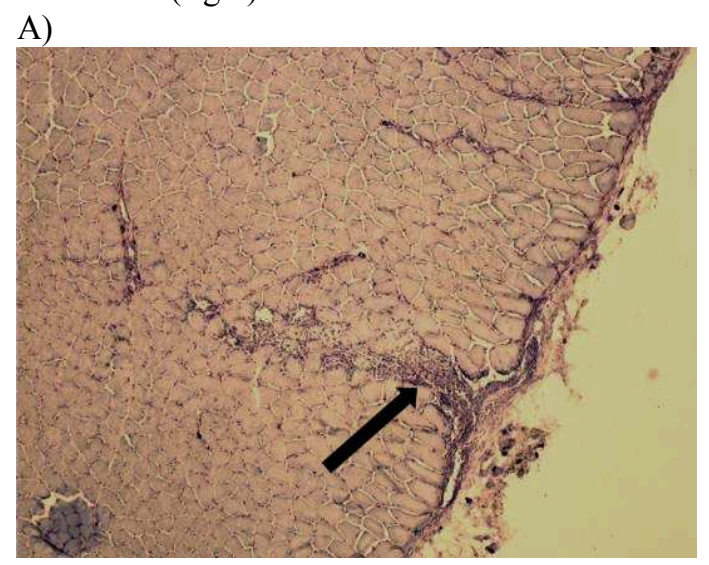

B)

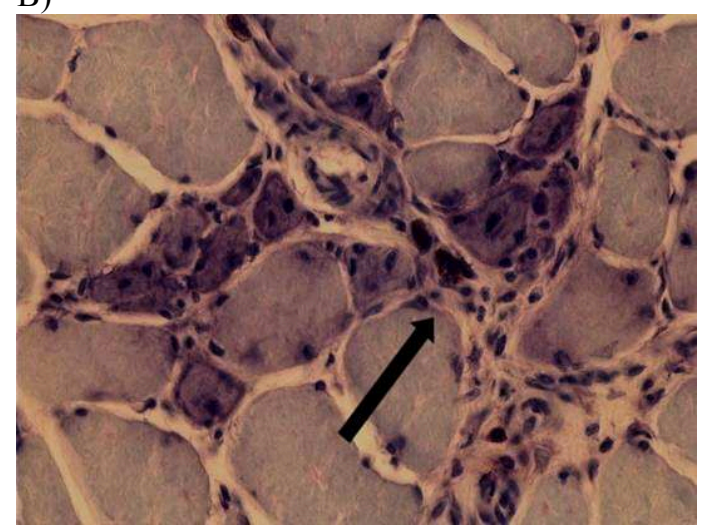

Fig.1: Lesion tracks stained in toluidine blue (black arrow), 5 days of stimulation, $3 \mathrm{~h}$ per day, magnification A) 5x, B) 40x

\section{Discussion:}

The results of this pilot study indicate that repeated impalement of muscles with wire electrodes causes minimal mechanical damage and the extent of this damage is similar independent of whether electrical current has been applied via the electrodes or not. We can assume that our stimulation protocol did not have undesired side effects on muscle structure and function. This notion is supported by previous observations on muscle injuries after voluntary running in wheels (Irintchev \& Wernig 1987). Daily running episodes cause necrosis and regeneration of muscle fibers within the first two weeks of wheel exercise. Although the extent of damage may reach $25 \%$ of all muscles fibers, tissue repair is very successful and no functional deficits are observed even after numerous cycles of muscle damage and repair (Irintchev \& Wernig 1987; Wernig et al., 1990).

\section{Acknowledgements:}

Special thanks to Heike Thieme and Med El

\section{Bibliography:}

[1] Cheetham J., Regner A., Jarvis J.C., Priest D., Sanders I., Soderholm L.V., Mitchell L.M., Ducharme N.G., Functional electrical stimulation of intrinsic laryngeal muscles under varying loads in exercising horses. PloS One. 2011, 6(8)

[2] Kim H.J., Park Y.S., Ryu J.S., Huh R., Han I., Shin D.A., Kim T.G., Cho K.G., Chung S.-S.: Intraoperative Facial Electromyography and Brainstem Auditory Evoked Potential Findings in Microvascular Decompression for Hemifacial Spasm: Correlation with Postoperative Delayed Facial Palsy. Stereotact Funct Neurosurg. 2012, 90(4):260-5

[3] Sanders I., Jacobs I., Wu B.L., Biller H.F. The three bellies of the canine posterior cricoarytenoid muscle: implications for understanding laryngeal function. Laryngoscope. $1993 \mathrm{Feb}$;103(2):171-7.

[4] Sanders I., Wu B.L., Mu L., Biller H.F. The innervation of the human posterior cricoarytenoid muscle: evidence for at least two neuromuscular compartments. Laryngoscope 1994 Jul;104(7):880-4.

[5] Colton R.H., Casper J.K. and Leonard, R. "Understanding voice problems: A physiological perspective for diagnosis and treatment (3rd ed.)", 2006, Baltimore, MD: Lippincott Williams and Wilkins

[6] Irintchev \& Werning (1987): Muscle damage and repair in voluntarily running mice: strain and muscle differences. Cell Tissue Res 1987, 249:509-521.

[7] Wernig A, Irintchev A, Weisshaupt P: Muscle injury, cross-sectional area and fibre type distribution in mouse soleus after intermittent wheel-running. J Physiol (Lond) 1990, 428: 639652 